\title{
Detection and monitoring of hypermethylated RASSF1A in serum from patients with metastatic breast cancer
}

\author{
Søren Kristiansen ${ }^{1 *}$, Dorte Nielsen² and György Sölétormos ${ }^{1}$
}

\begin{abstract}
Background: Circulating hypermethylated RASSFIA could be a novel and potential useful marker for monitoring patients with metastatic breast cancer. Technical obstacles include fragmentation of the circulating DNA, fluctuations in the concentration, low concentrations of circulating tumor DNA, and different locations of methylation in the RASSFIA gene among patients. One common method for detection of hypermethylated genes is sodium bisulfite conversion of non-methylated cytosine to uracil, followed by detection with PCR. However, the method relies on full conversion of all non-methylated cytosines, cause strand breaks, and loss of DNA. Alternatively, methylation-sensitive restriction enzymes have been used to digest genomic DNA, as well as sodium bisulfite-treated DNA. By flanking different regions of the RASSFIA with different PCR primer pairs, we analyzed for methylated genomic regions resistant to cleavage by the methylation-sensitive restriction enzymes Hpall and BstUI. The goal was to find region(s) in RASSF1A with high sensitivity and specificity that could be used for monitoring.

Results: The serum was spiked with non-human control DNA. By tracing the spiking control, the isolation procedure of the rare circulating tumor DNA was initially optimized. By analysis of production of PCR amplicons from Hpall- or BstUI-treated DNA isolated from 24 patients with metastatic breast cancer, we located four regions resulting in sensitivities from 63 to $83 \%$. When examining samples from 24 control subjects, these four regions gave a specificity of $100 \%$. Among these four regions, the primer pair with the highest PCR efficacy was selected to monitor the RASSF1A concentration in 31 collected serum samples. The spiked DNA was then used to calculate the tumor RASSFIA concentrations independent of fluctuations in circulating non-tumor DNA. As a proof of principle, there was concordance in the kinetics of the RASSF1A and the serological cancer biomarkers CA 15-3, CEA, and TPA.

Conclusions: Methylation-sensitive restriction enzymes may be a useful methodological approach for monitoring circulating hypermethylated RASSF1A among patients with metastatic breast cancer.
\end{abstract}

Keywords: DNA methylation, Epigenetics, Monitoring, Metastatic breast cancer, RASSF1A

\section{Background}

The clinical oncologist must assess and balance multiple information obtained from physical examinations, imaging techniques, a broad pallet of biochemical laboratory tests in blood, as well as pathological examinations of biopsies to make decisions whether the disease is under control and the adverse effects are acceptable [1].

Among patients with metastatic breast cancer, serological tumor markers alone are not recommended for

\footnotetext{
* Correspondence: skri0117@regionh.dk

'Department of Clinical Biochemistry, Nordsjællands Hospital-Hillerød, University of Copenhagen, Dyrehavevej 29, DK-3400 Hillerød, Denmark Full list of author information is available at the end of the article
}

monitoring the response to anticancer therapy [1]. An area of development of a new generation of blood-based cancer biomarkers for monitoring breast cancer patients could be hypermethylated tumor suppressor genes [2]. The cytosine in the genes is methylated by endogenous DNA methyltransferases with affinity for CpG dinucleotide motifs. The $\mathrm{CpG}$ motifs are condensed in $\mathrm{CpG}$ islands in the promoter regions, which are progressively more densely methylated during tumorigenesis. One method for detection of hypermethylated genes is sodium bisulfite conversion of non-methylated cytosine to uracil [3]. Since methylated cytosine is protected from conversion, primers and probes can then be designed to 
target hypermethylated genes, control genes, or regions not susceptible to methylation by PCR amplification of converted DNA [4]. However, the sodium bisulfite conversion of the DNA may be incomplete [5] and cause breaks in the DNA strands [6] and critical loss of total sample DNA [7, 8]. These critical issues may compromise the analytical detection of hypermethylated genes.

One candidate gene for development of a novel biomarker could be the RAS association (RalGDS/AF-6) domain family member 1A (RASSF1A) gene [9]. Close examination of the methylation status of RASSF1A reveals that hypermethylation occurs in the promoter and exon 1 region in a large percentage of human breast cancers [10], but the distinct location of the methylated CpGs are differentially distributed among different tumors [11]. Methylation profiling of individual tumors further suggests that DNA methylation progressively spreads from the first exon into the promoter area of the RASSF1A gene [11]. Furthermore, wide clonal intratumor heterogeneity of promoter hypermethylation of RASSF1A has been found in breast cancer [12]. Thus, there are both intra- and interindividual differences in the methylation profiles of the RASSF1A gene among tumors from different patients. Thus, one primer and probe design may not cover all types of RASSF1A methylation profiles, and the patient-to-patient variation may decrease the clinical sensitivity.

In a previous study, we used sodium bisulfiteconverted DNA and MethyLight to quantitate changes in serial concentrations of the hypermethylated RASSF1A in serum [13]. Serum samples were obtained from 29 patients with advanced breast cancer undergoing therapy and from 18 healthy control subjects [13]. Hypermethylated RASSF1A was not detected in serum samples obtained from the healthy women but was detected in all of the 29 patients at some time during monitoring. Hypermethylated RASSF1A was detected in a total of $45 \%$ of the 422 serial patient samples. Thus, RASSF $1 A$ was only periodically detected in some patients during monitoring. Furthermore, the collagen 2 A1 gene was used as a marker for the non-tumoral DNA concentration in the serum sample primers and used to normalize the RASSF1A concentration. However, the non-tumoral DNA concentration may not be constant in the blood due to a wide variety of confounding factors [14-17]. The acute effect of therapy may also cause a burst of DNA into the blood [18]. Thus, normalization of circulating tumor DNA to non-tumoral DNA may give false information regarding the status of the disease. Thus, bisulfite conversion [5-8], normalization of tumoral DNA to non-tumoral DNA [14-18], and one probe/primer design [10-12] may not be an optimal method for monitoring hypermethylated DNA among patients with metastatic breast cancer, as shown in the previous study [13].

In the present study, we have omitted the sodium bisulfite treatment and changed the methodological procedure. Firstly, we spiked the serum samples with external DNA. The spiking control was used to (1) optimize the DNA isolation steps and (2) to express the concentration of RASSF $1 A$ in $\mathrm{nmol} / \mathrm{ml}$. Thus, the concentration of hypermethylated RASSF1A was not depending on the fluctuating non-tumoral control DNA. Secondly, we used the restriction enzymes HpaII and BstUI to cleave unmethylated 5' -CCGG and 5'-CGCG motifs in the DNA to detect uncleaved hypermethylated RASSF1A. Thirdly, we also tested different primer pairs flanking different DNA regions of the RASSF1A gene to encounter for the intra- and interbiological variation of the methylation profile to ensure optimal sensitivity and specificity. Finally, as a proof of principle, the primer pair with the highest clinical sensitivity, specificity, and PCR performance were used to monitor serial changes in the concentrations of RASSF1A in serum obtained from a patient with metastatic breast cancer during therapy.

\section{Results}

Serum samples were obtained from 24 patients with metastatic breast cancer and from 24 age-matched healthy female as controls. The average concentrations of the protein tumor markers cancer-antigen 15-3 (CA 15-3), carcinoembryonic antigen (CEA), and tissue polypeptide antigen (TPA) among patients and healthy females are shown in Table 1. The concentrations spanned a wide range. The concentrations of CA 15-3, CEA, and TPA were significantly higher in serum from breast cancer patients as compared to the healthy females. In a few patients, the marker concentrations were below the cut of level. One sample had a CEA concentrations $<7.5 \mu \mathrm{g} / \mathrm{ml}$ and two samples had a TPA concentration $<357 \mathrm{U} / \mathrm{L}$, whereas all CA 15-3 concentrations were $>30 \mathrm{kU} / \mathrm{L}$. All the healthy females had CA 15-3, CEA, and TPA concentrations below the respective cut of levels.

Table 1 Protein tumor marker concentrations among the investigated patients with metastatic breast cancer and healthy females

\begin{tabular}{llll}
\hline & CA 15-3 (mean $\pm \mathrm{SE}, n=24)$ & $\mathrm{CEA}($ mean $\pm \mathrm{SE}, n=24)$ & $\mathrm{TPA}(\mathrm{mean} \pm \mathrm{SE}, n=24)$ \\
\hline Patients with metastatic breast cancer & $1552 \pm 384 \mathrm{kU} / \mathrm{L}^{\mathrm{a}}$ & $559.7 \pm 177 \mu \mathrm{g} / \mathrm{L}^{\mathrm{a}}$ & $2639 \pm 657 \mathrm{U} / \mathrm{L}^{\mathrm{a}}$ \\
Age-matched healthy females & $14.4 \pm 1.1 \mathrm{kU} / \mathrm{L}$ & $3.1 \pm 0.3 \mu \mathrm{g} / \mathrm{L}$ & $56.8 \pm 10.8 \mathrm{U} / \mathrm{L}$ \\
\hline
\end{tabular}

${ }^{a}$ Significantly different from age-matched control concentration $(p<0.05)$. The serum samples were used to isolate DNA, which was used to calculate the sensitivity and specificity of six different primer designs against hypermethylated RASSF1A 
Six different primer pairs were designed against RASSF1A promoter region and exon 1 (NG_02327.1, region 4562-5517). The primers targeted different locations of the gene and targeted different numbers of HpaII and BstUI cleaving motifs (Table 2). The investigated RASSF1A sequence contained 88 CpG dinucleotide sites, which may be aberrantly methylated as a response to neoplasia. Among these sites, there are seven HpaII and sixteen BstUI sites. The six designed primer pairs covered six HpaII and fourteen BstUI sites, covering $39 \%$ of all CpG sites. The base pair length of the designs was kept below $<300$ bp in order to maximize the chance of amplifying fragmented DNA [16].

To validate the six primer pairs, cDNA amplicons were produced and mock-digested or incubated with HpaII alone, or BstUI alone, respectively. Since PCR amplicons are not methylated, all HpaII or BstUI cleavage motifs will be cleaved in the amplicons. The digest was separated on $1 \times$ TBE ethidium-stained agarose gels, as shown in Fig. 1. Primer pairs designed to contain exclusively HpaII cleavage sites, BstUI sites, or both type of cleavage sites, displayed a digestion profile as expected. However, the 288-bp amplicon produced with primer 32 was calculated to be reduced to $279 \mathrm{bp}$ after BstUI cleavage. This minor reduction in base pair length was not visually detectable by agarose-electrophoresis.

Productions of amplicons from HpaII- or BstUItreated serum DNA from 24 metastatic breast cancer patients and 24 healthy controls were then used to calculate the sensitivity and specificity. This was plotted in a receiver operating characteristic (ROC) curve, as shown in Fig. 2. When DNA was BstUI-treated and subsequently PCR amplified with primer pair 66, amplicons was detected in 20 of 24 serum samples (83\% sensitivity) isolated from metastatic breast cancer patients. In contrast, no amplicons were produced when using DNA isolated from serum obtained from 24 healthy females (100\% specificity). This design targeting five BstUI sites distal to the initiation site of RASSF1A gave the highest AUC in the ROC plot relative to the eight other primer combinations. Primer $50 \mathrm{HpaII}, 54 \mathrm{BstUI}$, and $32 \mathrm{HpAII}$ had a clinical specificity of $100 \%$, but the sensitivity was relatively lower, 71,71 , and $63 \%$, respectively.

Since monitoring require precise measurements of the serial concentrations of rare tumor DNA, the four primer pairs with $100 \%$ clinical specificity were then tested for their analytical imprecision in terms of coefficient of variation, PCR amplification factor, efficiency, linearity, and limits of detection. As shown in Fig. 3, PCR amplification with primer 50 developed a signal linear over a $10^{6}$-fold change in DNA concentration, an amplification factor of 1.98 and efficiency of $98.02 \%$. The analytical coefficient of variation was $13.2 \%(n=30$ determinations), and the limit of detection was $0.01 \mathrm{ng} / \mathrm{ml}$ of DNA. Overall, primer 50 was marginally superior to the three other primer pairs and was selected to amplify HpaII-treated DNA isolated from the serum samples.

Table 2 Overview of the methylation profile of RASSFIA

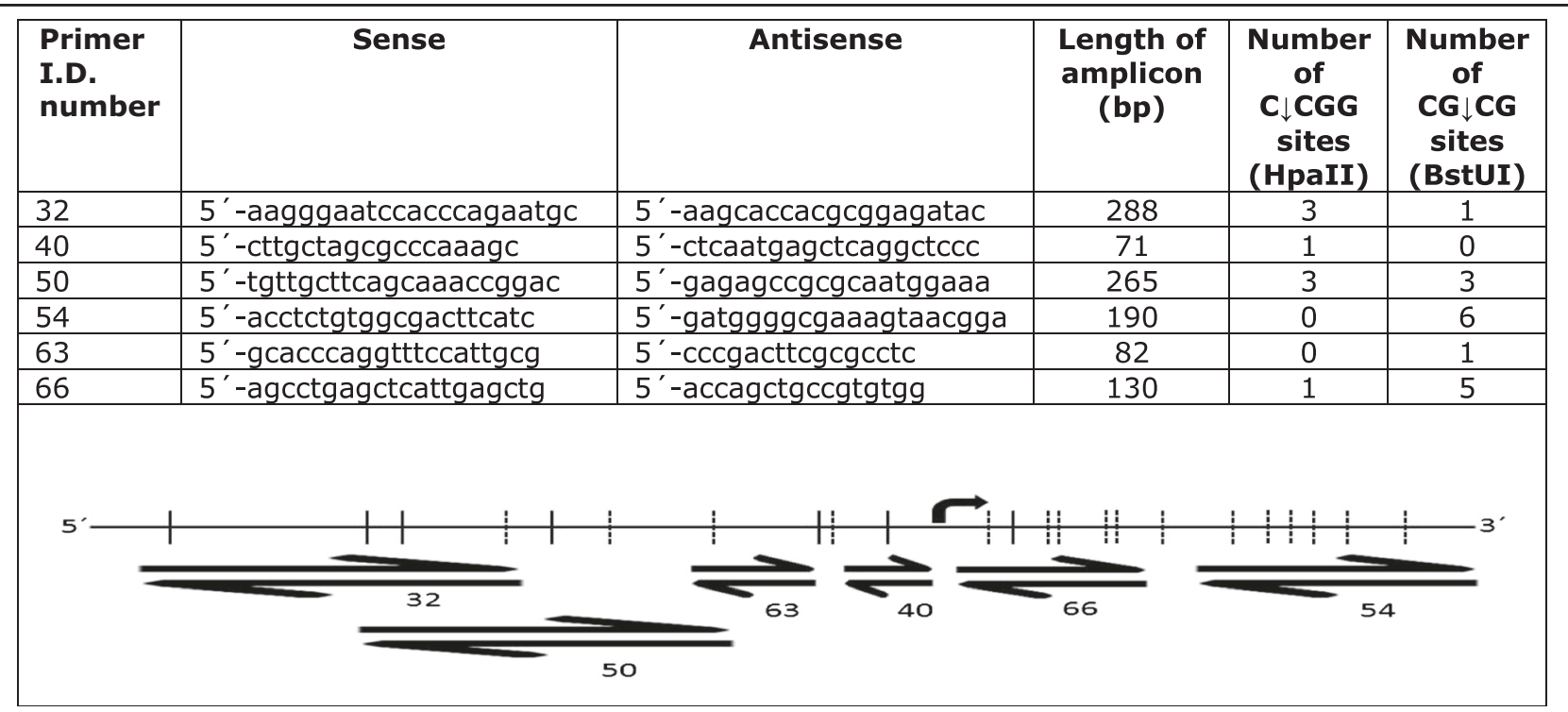

The sequences of six different primer pairs designed against RASSF1A, the length of the amplicon, and the number of C $\downarrow$ CGG and CG $\downarrow C G$ sites for each primer pair are shown in the upper panel

The lower panel shows the location of C $\downarrow C G G$ (solid line) and CG $\downarrow C G$ (broken line) cleavage sites in RASSF1A. The primer pairs were designed to target these C $\downarrow$ CGG and CG $\downarrow C G$ sites. Methylation of the cytosine in the CpG dinucleotide motif within the C $\downarrow$ CGG and CG $\downarrow C G$ sites protects against enzymatic restriction cutting by Hpall and BstUI, respectively, and enables formation of amplicons. Unmethylation results in digestion of the target and no formation of amplicons. The location of the initiation site by the codon ATG is show by an arrow 

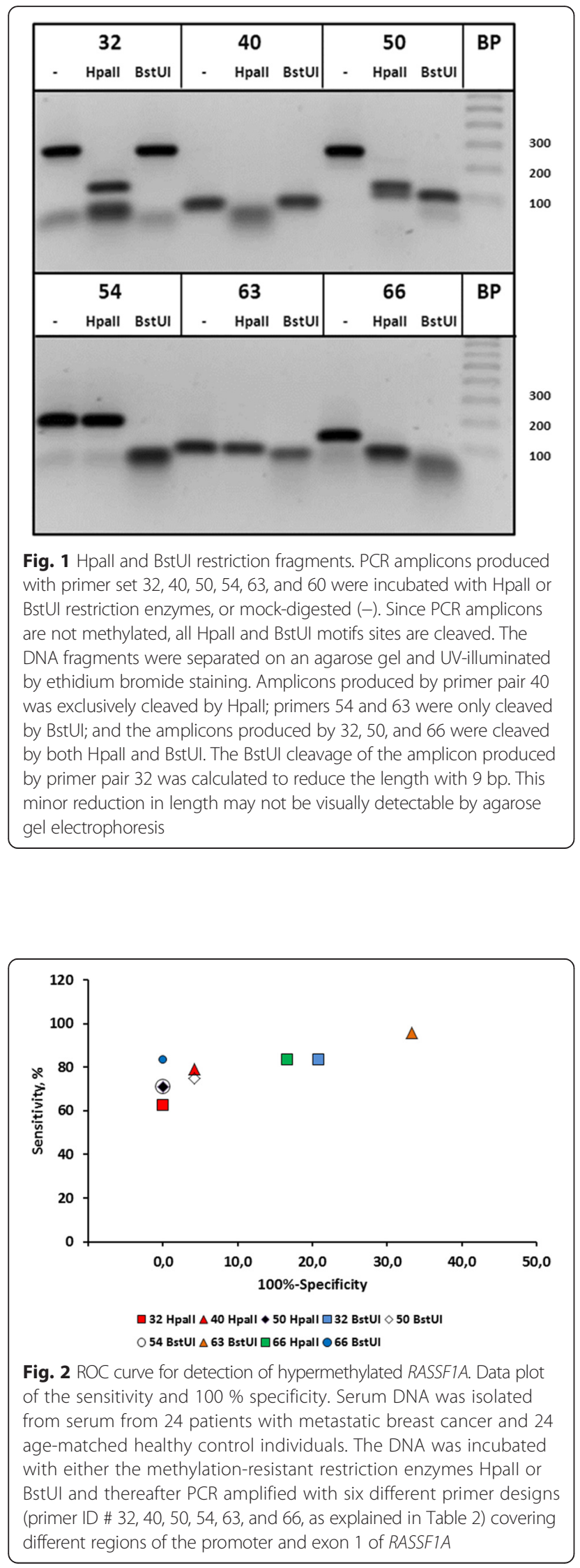

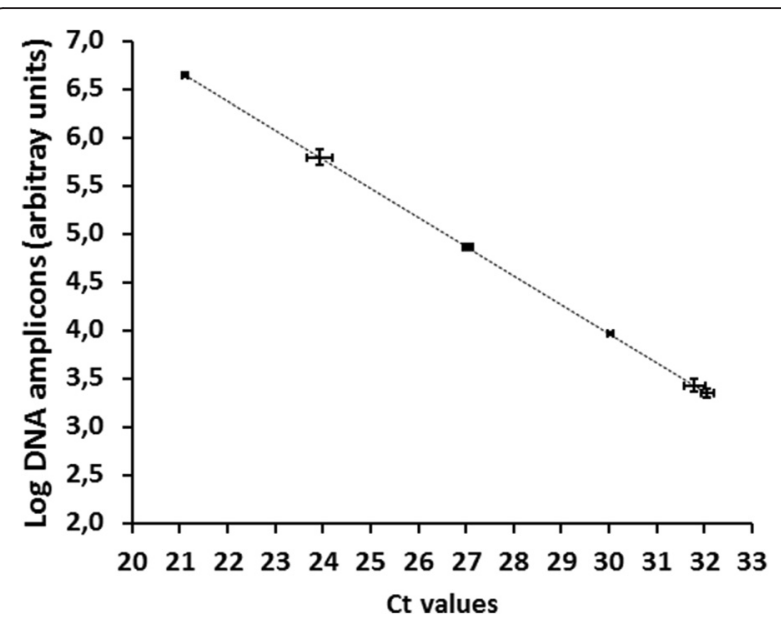

Fig. 3 Correlation of the Ct values and logarithmic DNA amplicons. DNA was diluted sequentially tenfold and PCR amplified with primer no. 50. Each measurement was performed as triplicates (mean \pm SD). $\mathrm{Ct}$ (cycle threshold) is defined as the number of cycles required for the fluorescent signal to cross the threshold

The average concentration of the hypermethylated RASSF1A using all primer designs was plotted against the serum concentrations of the tumor burden markers CA 15-3 and CEA and the tumor activity marker TPA. As shown in Fig. 4, there was a concordance of the concentrations of TPA with the concentrations of the hypermethylated RASSF1A. There was discordance of the CA-15-3 and CEA concentrations with the hypermethylated RASSF1A concentrations.

As the first proof of principle, 31 independent serial data for the tumor markers CA 15-3, CEA, TPA and hypermethylated RASSF1A for one patient $\mathrm{A}$ is shown in Fig. 5. Overall, there was concordance with the change in tumor marker concentrations and the change in RASSF1A concentrations.

\section{Discussion}

Hypermethylation of the RASSF1A gene is a prime candidate among many genes as a potential novel biomarker for stage I-IV breast cancer and have been investigated for early detection of cancer, diagnosis, prognosis for the patient, prediction of the effect of therapy, and monitoring of the effect of therapy by measuring the circulating biomarker concentration (reviewed in [9]). In a previous study, we monitored circulating hypermethylated RASSF1A and showed concordance with the kinetics of CA 15-3, CEA, and TPA but also the periodical lack of RASSF1A detection in some patients with advanced breast cancer [13]. The periodical lack of detection could be due to in situ subdetectable concentrations and/or due to an analytical problem with sodium bisulfite conversion of fragmented DNA [13]. 


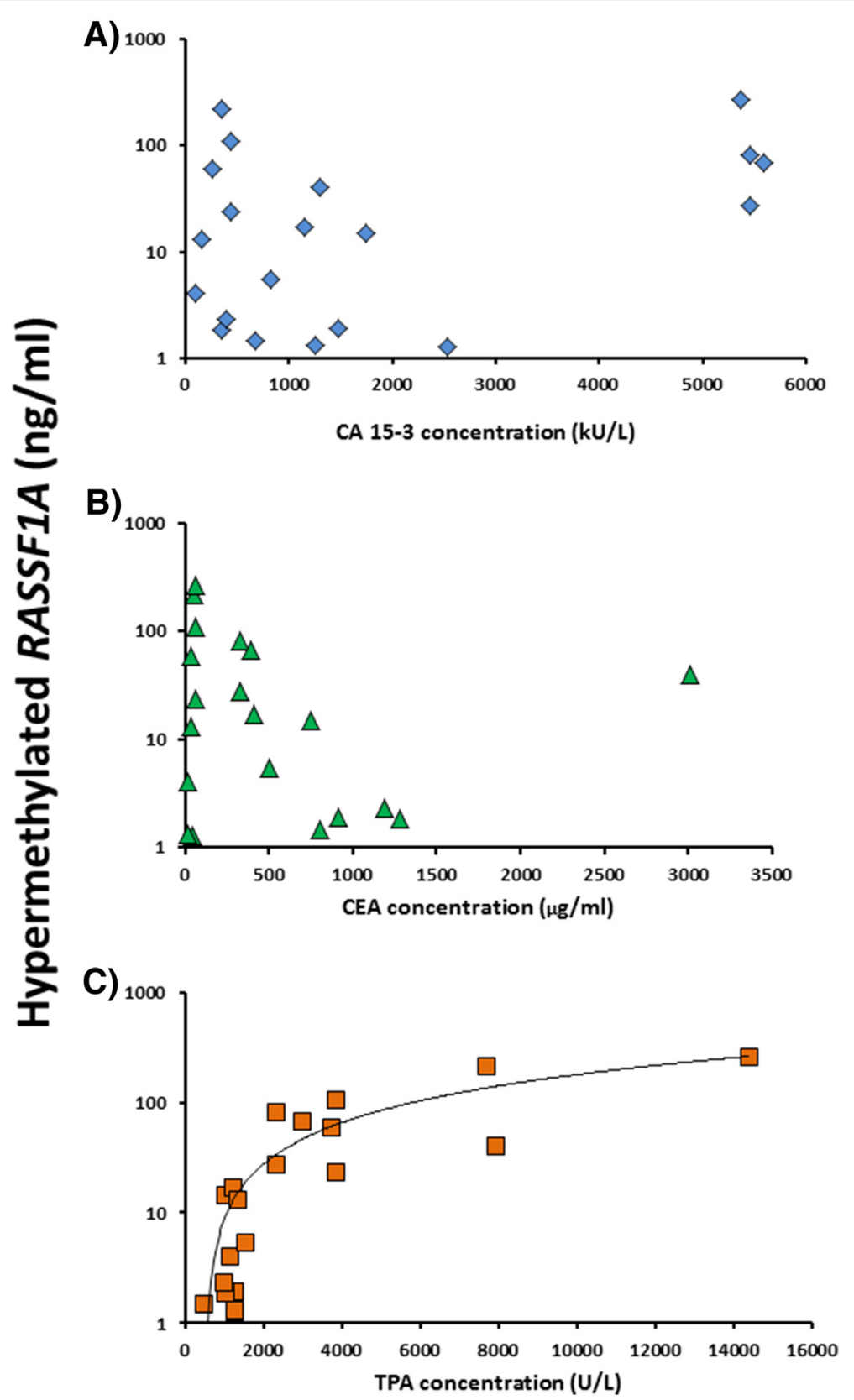

Fig. 4 Correlation between the concentrations of the protein tumor markers and hypermethylated RASSFIA based on the cross-sectional samples from each of the 24 patients. The serum concentration of CA 15-3 (a), CEA (b), and TPA (c) are plotted against the average hypermethylated RASSF1A concentration determined by using all six primer designs. The data was obtained from 24 serum samples collected from patients with metastatic breast cancer

In the present study, we have optimized the steps for isolating the rare serological tumor DNA fragments by tracing a spiking control. Instead of using sodium bisulfite treatment of DNA, we used restriction enzymes; these are sensitive to methylation of the CpG motif in the cleavage site. By using restriction enzyme-treated as DNA template, flanking primer pairs were used to amplify different locations of RASSF1A. The different designs were tested for optimal sensitivity, specificity, and PCR performance. With this method, we found a sensitivity of $63-83 \%$ at a specificity of $100 \%$ when testing 24 cross-sectional samples collected from metastatic breast patients and healthy females.

In the four previous cross-sectional studies of sodium bisulfite-converted DNA, the circulating hypermethylated RASSF1A was detected in metastatic breast cancer patients [19-22]. Tan et al. [19] detected RASSF1A in $42 \%$ (8 out of 19) of the serum samples with a 

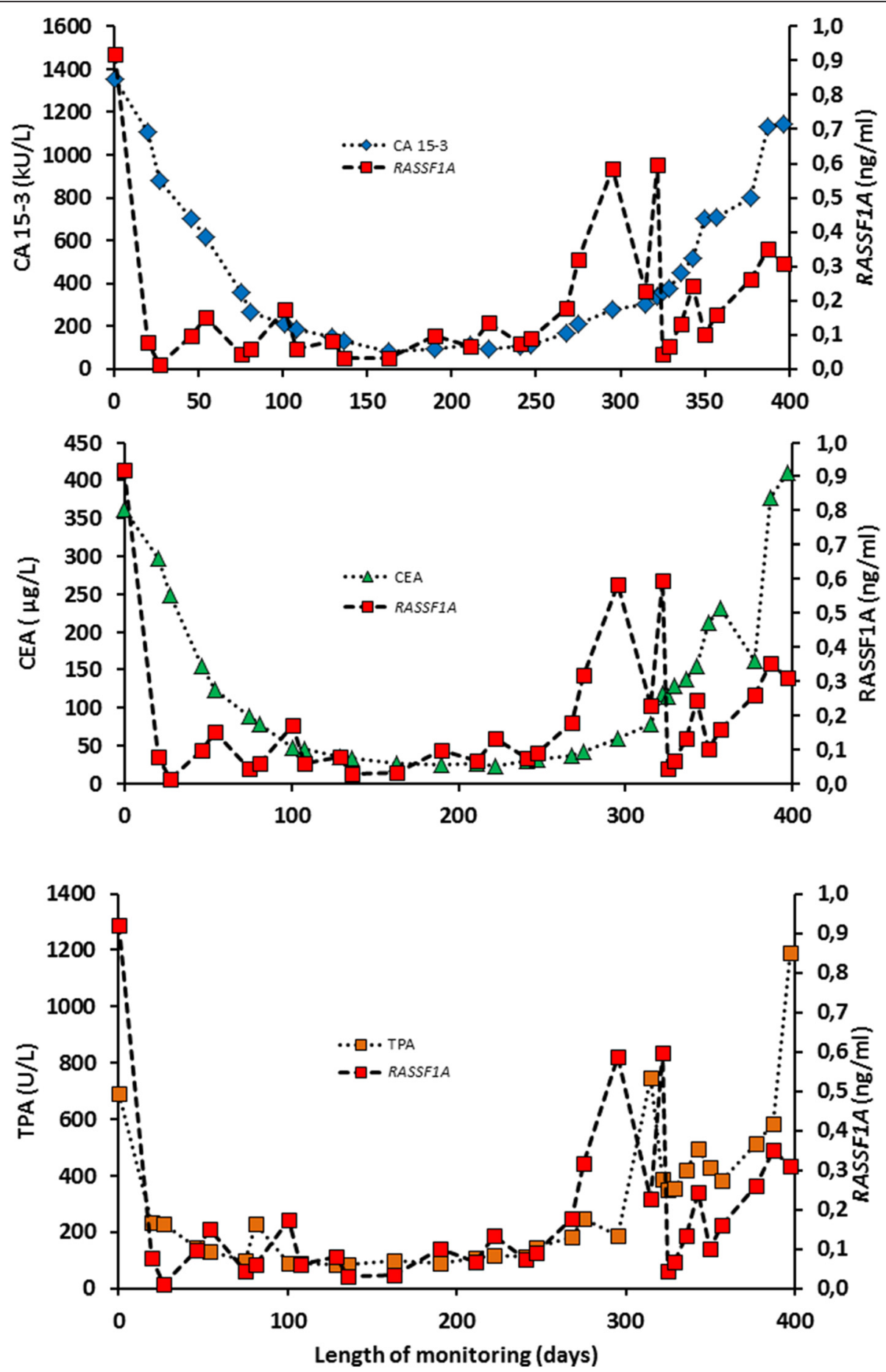

Fig. 5 Monitoring of patient A with metastatic breast cancer during therapy. Three panels with serial concentrations of the protein biomarkers CA 15-3, CEA, TPA and the concentrations of hypermethylated RASSF1A

technique based on methylation-specific PCR of sodium bisulfite-converted DNA. The other studies [20,21] both used the MethyLight PCR technique but with different primers and probes raised against sodium bisulfiteconverted DNA. Matuschek et al. [20] detected RASSF1A in $43 \%$ (10 out of 23) of the serum samples, whereas Van der Auwera et al. [21] detected 35 \% (28 out of 79). Fackler et al. [22] used the cMethDNA assay to determine the concentrations of ten individual genes. The assay is depending on the input of sodium bisulfiteconverted DNA, which are amplified in two sequential PCR reactions; first, multiplex PCR amplification of the 
ten genes with external primers, then followed by quantification of individual genes by real-time methylationspecific PCR reaction. Detection of RASSF1A alone was achieved in $70 \%$ (40 out of 57) of the training and test samples, but the sensitivity was raised to $91 \%$ at a specificity of $96 \%$ when combining the panel of genes. Taken together, in these studies using different methods, but bisulfite-converted DNA, the sensitivity was in the range of 35-70 \% [19-22]. In the present study, using input of genomic DNA, two different methylation-sensitive restriction enzymes, the sensitivity was $63-80 \%$ at a specificity of $100 \%$ for four different regions of RASSF1A. In contrast, the low sensitivities for detection of RASSF1A in the other studies could be due sodium bisulfite conversion of DNA, which may limit the amount of the rare tumor DNA [19-21, 23]. Thus, detection of genes in a panel with methylation-sensitive restriction enzymedigested DNA as assay input should be further investigated.

The large span and variations in the CA 15-3, CEA, and TPA concentrations among the cross-sectional samples were used to test for correlation between the protein biomarkers and hypermethylated RASSF1A concentrations (Fig. 4). The CA 15-3 assay is based on the monoclonal antibodies 115D8 and DF3 which are both raised against the human MUC1 protein. The CEA molecule is a glycoprotein involved in cell adhesion; it is a glycosylphosphatidylinositol cell surface anchored glycoprotein that is released in to the bloodstream of cancer patients and healthy individuals. Being a secretory product, both CA 15-3 and CEA are considered as serological markers of changing tumor burden in the individual patient. TPA belongs to the cytoskeleton proteins circulating as a complex of soluble proteolytic polypeptide fragments of cytokeratins 8,18 , and 19 . The TPA release may indicate cell turnover and the information supplied by the TPA may be distinctly different from the information supplied by the markers of tumor burden CA 15-3 and CEA [24]. As shown in Fig. 4, the present preliminary results may suggest that circulating hypermethylated RASSF1A may be a biomarker for cell turnover and/or cell death by apoptosis/necrosis. However, as shown in Fig. 5, we found concordance with hypermethylated RASSF1A with the kinetics of CA 15-3, CEA, and TPA. This may be due to the similar kinetics of the three markers CA 15-3, CEA, and TPA.

Monitoring of the changes in serial biomarker concentration requires an analytical method with a low-aspossible analytical coefficient of variation [25]. When the concentration of circulating tumor DNA is expressed relatively to the circulating non-tumor DNA, the change in concentration may be misleading. In the present study, we used a spiking control to account for small pre-analytical variations in the DNA concentrations.
Spiking of serum samples has previously been used by Fackler et al. [22] to facilitate quantification of tumor DNA. The optimal location in the RASSF1A gene and PCR performance were then used to monitor metastatic breast cancer patients during therapy. As a proof of principle, 31 serial samples were monitored with the tumor markers CA 15-3, CEA, and TPA and compared with the changes in the hypermethylated RASSF1A concentrations. In the present study, and in the previous study [13], concordance could be observed between serial changes of the hypermethylated RASSF1A gene and the protein markers.

\section{Conclusion}

In conclusion, it is suggested to use methylationsensitive restrictive enzymes as an alternative to the time-consuming sodium bisulfite step, which also may reduce the amount of tumor DNA. Circulating hypermethylated RASSF1A and protein markers may have similar kinetics during monitoring. Future studies are required to define criteria for changes in tumor DNA to assess the disease status. These criteria should be used to explore the clinical utility of monitoring circulating RASSF1A.

\section{Methods}

\section{Healthy subjects}

Women among the healthy staff at the Departments of Oncology and Clinical Chemistry, Herlev Hospital, University of Copenhagen, Denmark, volunteered to participate in the study from 1990 to 1992 [26]. All subjects gave informed consent to their participation, and the study was approved by the regional Ethical Committee (KA 93076). All subjects stated they were free of disease at the time of the study, and none had any known chronic or recurrent illness or was taking any medication. The subjects continued their usual lifestyle during the period of the study. No investigations were performed to exclude asymptomatic breast cancer. Serum samples was stored at $-80{ }^{\circ} \mathrm{C}$ and later used for detection of hypermethylated RASSF1A.

\section{Patients with metastatic breast cancer}

The investigated patients had histologically proven advanced progressive breast cancer (stage IV) with measurable or evaluable disease $[26,27]$. They received epirubicin $70 \mathrm{mg} / \mathrm{m}^{2}$ on days 1 and 8 every 4 weeks. Epirubicin was continued until progressive disease (PD) was noted or until a maximum cumulative dose of $1000 \mathrm{mg} / \mathrm{m}^{2}$ had been administered. Clinical response evaluations at that time of the study (1988 to 1991) were based on the criteria of the World Health Organization [28] and performed by investigators without knowledge of the tumor marker data. Blood specimens for CA 15-3, 
CEA, and TPA analysis were sampled before each treatment cycle $[26,27]$. At each sampling, the serum specimen used for analysis of the protein tumor markers was saved in different aliquots at $-80{ }^{\circ} \mathrm{C}$ and used for the current analysis of hypermethylated DNA. The study complied with the Helsinki II Declaration and was approved by the Scientific Ethics Committee of Copenhagen County (KA 89257, H-D-2009-048).

\section{Isolation of tumor DNA}

One milliliter of serum from the bio bank was quickthawed and spiked with a constant amount of PBR322 plasmid (Life Technologies). The spiking control was traced during all the isolation steps. The spiked serum was immediately transferred to $1 \mathrm{ml}$ of binding buffer supplemented with RNA carrier. The DNA isolation was carried out as suggested by Roche Diagnostics (High Pure Viral Nucleic Acid Large Volume Kit), except that the DNA and tracer were eluted with $0.1 \mathrm{ml}$ of Tango buffer (Fisher Scientific). The DNA capturing efficiency of column filters was investigated by repassing the sample DNA on the columns. One DNA capturing cycle was found sufficient (data not shown). The eluting efficiency of the captured DNA from the filters was investigated by eluting filters with different volumes of elute buffer (buffer suggested by the manufacturer), water, or Tango buffer. The optimal method was to elute the DNA from filters with $100 \mu \mathrm{l}$ of Tango buffer. There was no difference between the recovery and relative concentration of human DNA versus the spiking control plasmid. Consequently, the spiking control could be used to normalize for small fluctuations in DNA recovery. Twenty microliters of eluted DNA was added to $10 \mathrm{U}$ of BstUI or HpaII (Fisher Scientific). Samples were incubated for $16 \mathrm{~h}$ at $37{ }^{\circ} \mathrm{C}$ followed by $20 \mathrm{~min}$ at $95{ }^{\circ} \mathrm{C}$. The digested DNA sample was added $10 \times$ volume of DNA-free water (Sigma-Aldrich) and stored at $-20^{\circ} \mathrm{C}$.

\section{Detection of hypermethylated RASSF1A}

The detection of hypermethylated RASSF1A was based on the restriction enzymes HpaII and BstUI that cleaves unmethylated 5'-CCGG and 5'-CGCG motifs, respectively [29]. Notably, methylations of CpG in the cleavage motifs remain intact and detectable by real-time PCR. The PCR amplifications were done in duplicates of $20 \mu \mathrm{l}$ each containing $250 \mathrm{pmol} / \mathrm{L}$ of primer using the Power SYBR Green PCR Master Kit (Life Technologies). The PCR was carried out on a 7500 Fast Real-Time PCR apparatus (Applied Biosystems). The inhibitory effect of interfering $\mathrm{Mg}^{++}$from the Tango buffer on PCR amplification process was investigated. A final concentration of $3 \%$ Tango buffer was found to have no influence on the efficiency of the PCR amplification. A primer set was designed against the spiking control to cover HpaII and BstUI cleavage motifs.
This primer set was used to validate for $100 \%$ cleavage efficiency of all DNA samples. A time-course study revealed that all PCR amplicons and the spiking control were $100 \%$ cut after $2 \mathrm{~h}$ of incubation at $37^{\circ} \mathrm{C}$. As a standard, the incubation time was set to $16 \mathrm{~h}$. Furthermore, a restriction-insensitive primer set was designed against a DNA region in the spiking control that did not contain HpaII and BstUI cleavage motifs. After PCR amplification of HpaII- or BstUI-pretreated DNA, the original serum concentration of hypermethylated RASSF1A was then expressed in $\mathrm{ng} / \mathrm{ml}$ by using a DNA standard curve and with minor corrections for changes in DNA recovery.

\section{Availability of supporting data}

None.

\section{Abbreviations}

CA 15-3: cancer-antigen 15-3; CEA: carcinoembryonic antigen; TPA: tissue polypeptide antigen; RASSF1A gene: RAS association (RalGDS/AF-6) domain family member $1 \mathrm{~A}$.

\section{Competing interests}

The authors declare that they have no competing interests.

\section{Authors' contributions}

SK has made substantial contributions to the conception, design of study, analysis and interpretation of data, and drafted the manuscript. GS and DN were involved in the management and treatment of patients, acquisition of samples and patient data, and revised the manuscript critically for important intellectual content. All authors take public responsibility for appropriate portions of the content. All authors read and approved the final manuscript.

\section{Authors' information}

Not relevant.

\section{Acknowledgements}

Søren Kristiansen received research grants from the Nordsjællands Hospital, Hillerød, the Foundation of Maren and Jens Thestrup, and the Foundation of Olga Bryde Nielsen.

\section{Author details}

${ }^{1}$ Department of Clinical Biochemistry, Nordsjællands Hospital-Hillerød, University of Copenhagen, Dyrehavevej 29, DK-3400 Hillerød, Denmark. ${ }^{2}$ Department of Oncology, Herlev Hospital, University of Copenhagen, Herlev Ringvej 75, 2730 Herlev, Denmark.

Received: 24 November 2015 Accepted: 9 March 2016

Published online: 01 April 2016

\footnotetext{
References

1. National Comprehensive Cancer Network: NCCN, Clinical practice guidelines in oncology. Version 2.2013, http://www.NCCN.org. Accessed 30 Apr 2016.

2. Esteller M. Epigenetics provides a new generation of oncogenes and tumour-suppressor genes. Br J Cancer. 2007;96:26-30.

3. Hayatsu $H$, Wataya $Y$, Kai K, lida S. Reaction of sodium bisulfite with uracil, cytosine, and their derivatives. Biochemistry. 1970;9:2858-65.

4. Eads CA, Danenberg KD, Kawakami K, Saltz LB, Blake C, Shibata D, et al. MethyLight: a high-throughput assay to measure DNA methylation. Nucleic Acids Res. 2000:28:E32.

5. Genereux DP, Johnson WC, Burden AF, Stoger R, Laird CD. Errors in the bisulfite conversion of DNA: Modulating inappropriate- and failedconversion frequencies. Nucleic Acids Res. 2008;36:e150.

6. Suzuki T, Ohsumi S, Makino K. Mechanistic studies on depurination and apurinic site chain breakage in oligodeoxyribonucleotides. Nucleic Acids Res. 1994;22:4997-5003.

7. Tanaka K, Okamoto A. Degradation of DNA by bisulfite treatment. Bioorg Med Chem Lett. 2007;17:1912-5.
} 
8. Grunau C, Clark SJ, Rosenthal A. Bisulfite genomic sequencing: systematic investigation of critical experimental parameters. Nucleic Acids Res. 2001;29:E65-5.

9. Kristiansen S, Jørgensen LM, Guldberg P, Sölétormos G. Aberrantly methylated DNA as a biomarker in breast cancer. Int J Biol Markers. 2013;28:141-50

10. Dammann R, Yang G, Pfeifer GP. Hypermethylation of the cpG island of Ras association domain family $1 \mathrm{~A}$ (RASSF1A), a putative tumor suppressor gene from the 3 p21.3 locus, occurs in a large percentage of human breast cancers. Cancer Res. 2001;61:3105-9.

11. Yan PS, Shi H, Rahmatpanah F, Hsiau TH, Hsiau AH, Leu YW, et al. Differential distribution of DNA methylation within the RASSF1A CpG island in breast cancer. Cancer Res. 2003:63:6178-86.

12. Moelans $C B$, de Groot JS, Pan X, van der Wall E, van Diest PJ. Clonal intratumor heterogeneity of promoter hypermethylation in breast cancer by MS-MLPA. Mod Pathol. 2014;27:869-74.

13. Kristiansen $\mathrm{S}$, Jørgensen $\mathrm{LM}$, Hansen MH, Nielsen D, Soletormos $G$ Concordance of hypermethylated DNA and the tumor markers CA 15-3, CEA, and TPA in serum during monitoring of patients with advanced breast cancer. BioMed Res Int. 2015. doi:10.1155/2015/986024.

14. Heitzer E, Ulz P, Geigl JB. Circulating tumor DNA as a liquid biopsy for cancer. Clin Chem. 2015;61:12-23.

15. van der Vaart M, Pretorius PJ. Circulating DNA. Its origin and fluctuation. Ann N Y Acad Sci. 2008;1137:18-26.

16. Jahr $\mathrm{S}$, Hentze $\mathrm{H}$, Englisch $\mathrm{S}$, Hardt D, Fackelmayer FO, Hesch RD, et al. DNA fragments in the blood plasma of cancer patients: quantitations and evidence for their origin from apoptotic and necrotic cells. Cancer Res. 2001;61:1659-65.

17. Anker P, Stroun M, Maurice PA. Spontaneous release of DNA by human blood lymphocytes as shown in an in vitro system. Cancer Res. 1975;35:2375-82

18. Yasasever V, Dincer M, Camlica H, Karaloglu D, Dalay N. Utility of CA 15-3 and CEA in monitoring breast cancer patients with bone metastases: special emphasis on "spiking" phenomena. Clin Biochem. 1997;30:53-6.

19. Tan SH, Ida H, Lau QC, Goh BC, Chieng WS, Loh M, et al. Detection of promoter hypermethylation in serum samples of cancer patients by methylation-specific polymerase chain reaction for tumour suppressor genes including RUNX3. Oncol Rep. 2007:18:1225-30.

20. Matuschek C, Bolke E, Lammering G, Gerber PA, Peiper M, Budach W, et al. Methylated APC and GSTP1 genes in serum DNA correlate with the presence of circulating blood tumor cells and are associated with a more aggressive and advanced breast cancer disease. Eur J Med Res. 2010;15:277-86

21. Van der Auwera I, Elst HJ, Van Laere SJ, Maes H, Huget P, van Dam P, et al. The presence of circulating total DNA and methylated genes is associated with circulating tumour cells in blood from breast cancer patients. Br J Cancer. 2009:100:1277-86.

22. Fackler MJ, Lopez Bujanda Z, Umbricht C, Teo WW, Cho S, Zhang Z, et al. Novel methylated biomarkers and a robust assay to detect circulating tumor DNA in metastatic breast cancer. Cancer Res. 2014;74:2160-70.

23. Kristiansen $\mathrm{S}$, Nielsen D, Sölétormos G. Methylated DNA for monitoring tumor growth and regression: how do we get there? Crit Rev Clin Lab Sci. 2014:51:149-59.

24. Sölétormos G. Serological tumor markers for monitoring breast cancer. Dan Med Bull. 2001:48:229-55.

25. Fraser CG, Hyltoft-Petersen P, Larsen ML. Setting analytical goals for random analytical error in specific clinical monitoring situations. Clin Chem. 1990;36:1625-8

26. Sölétormos G, Nielsen D, Schioler V, Skovsgaard T, Dombernowsky P. Tumor markers cancer antigen 15.3, carcinoembryonic antigen, and tissue polypeptide antigen for monitoring metastatic breast cancer during firstline chemotherapy and follow-up. Clin Chem. 1996:42:564-75.

27. Nielsen D, Dombernowsky P, Larsen SK, Hansen OP, Skovsgaard T. Epirubicin or epirubicin and cisplatin as first-line therapy in advanced breast cancer. A phase III study. Cancer Chemother Pharmacol. 2000;46:459-66.

28. World Health Organization. WHO handbook for reporting results of cancer treatment. Geneva: World Health Organization; 1979. Http://whqlibdoc.who. int/offset/WHO_OFFSET_48.pdf.

29. Ruiz-Garcia L, Cabezas JA, de Maria N, Cervera MT. Isoschizomers and amplified fragment length polymorphism for the detection of specific cytosine methylation changes. Methods Mol Biol. 2010;631:63-74.

\section{Submit your next manuscript to BioMed Central and we will help you at every step:}

- We accept pre-submission inquiries

- Our selector tool helps you to find the most relevant journal

- We provide round the clock customer support

- Convenient online submission

- Thorough peer review

- Inclusion in PubMed and all major indexing services

- Maximum visibility for your research

Submit your manuscript at www.biomedcentral.com/submit
() BioMed Central 